\title{
Dermatoglyphics in the 18q-Syndrome
}

\author{
Chris (: Piato) ${ }^{117]}$, Wiadimir Werteilecki, Park S. Gerald, and Jerry 1). Niswander \\ National Institute of C:hild Health and Human Development and National Cancer Institute, National Institutes of Health, Bethesda, \\ Maryland; Boston C'hildren's Hospital Medical Center, Boston, Massachusetts; and National Institute of Dental Research, \\ National Institutes of Health, Bethesda, Maryland, USA
}

\begin{abstract}
Extract
The dermatoglyphics of 6 (aucasian patients with partial deletion of the long arm of chromosome 18 (18q-syndrome) were studied together with those of their parents and normal sibs. $A$ second control sample, consisting of 19 randomly selected Caucasian families, was used for comparison.

The patients showed significantly higher pattern intensity index, mainly higher frequency of whorls on their fingers. The direction of the main palmar lines was also significantly more transverse. 'The distribution of pattern intensity index, however, and the main line terminations of the parents and sibs of the patients were similar to those of the control families.
\end{abstract}

\section{Speculation}

The present study indicates the relevance of dermatoglyphics as an aid in the diagnosis of the 18c-syndrome, and reveals the usefulness of intrafamily comparisons in establishing dermatoglyphic peculiarities, especially when dealing with small samples.

\section{Introduction}

The first patient with partial deletion of the long am of a 17-18 chromosome was described by de Grouchy et al. [i]. Shortly thereafter, this cytogenetic anomaly served as the basis for the recognition of a new clinical syndrome by Lejeune ol al. $[9]$ and Wertelecki al al. [15], herein referred to as the I8q-syndrome. The clinical diagnostic criteria have changed little since our first report and are summarized in Table $I$.

These studies suggest that the 18q-patients have an excess of whorls on their fingers. It is the objective of the present study to craluate in detail the significance of the fingerprint patterns and other dermatoglyphic features in six patients with 18 p-syndrome and to atscertain whether these features are also encountered in other family members.

\section{Matrials and Mrithods}

All six casen were first diagnosed at the Clinical cenetics Division of Boston Children's Hospital Medical
Center. Clinical and cytogenetic details are described by Wertelecki and Gerald [1.1]. The nature and amount of genetic material deleted are probably not the same in each of the six unrelated patients.

Palm prints and fingerprints were collected from patients and their first degree relatives by the standard ink method. Nineteen control fimnilies (with 55 normal children) were selected at random from a control sample previously studied by Niswander and Adams [11]. The pattients and controls were all Calucasian.

All dematoglyphics were evaluated for the following features: (I) fingerprint patterns and ridge count using single count in whorls as described by Holt [7]; (2) pattern intensity index, which is the sum of the coded values of the total finger patterns and serves as a measure of fingerprint pattern complexity. The values of 0,1 , and 2 were assigned to arches, loops, and whorls, respectively; (3) main line terminations, with special emphasis on the modal types of the D) line (Fig. 1) as described by Cummins and Midlo [2, 3]. The modil types of the $D$ line serve an indicators of the 
Table I. Man clinical diagnestic signs of the 18q-syndrome

\begin{tabular}{|c|c|c|c|c|c|c|}
\hline & & & & sest & & \\
\hline & I & 1I & III & IV & I & II \\
\hline - & & & & . . - & & $\cdots-$ \\
\hline Mental retardation (IC) & $\begin{array}{l}+ \\
(i 2)\end{array}$ & $\begin{array}{c}+ \\
(45)\end{array}$ & $\begin{array}{c}+ \\
(42)\end{array}$ & $\begin{array}{c}+ \\
(85 i)\end{array}$ & + & $\begin{array}{c}+ \\
(46)\end{array}$ \\
\hline Short stature & + & + & + & - & + & + \\
\hline Characteristic facies & + & + & + & + & + & + \\
\hline $\begin{array}{l}\text { Prominent antihclix } \\
\text { and/or antitragus }\end{array}$ & +- & + & + & + & + & + \\
\hline $\begin{array}{l}\text { Narrow or atretic exter } \\
\text { nal car canal }\end{array}$ & + & + & + & - & - & + \\
\hline $\begin{array}{l}\text { Hearing loss (usually } \\
\text { conductive) }\end{array}$ & + & + & + & + & - & + \\
\hline llorizontal nystagumus & + & + & - & + & - & + \\
\hline Generalized hypotonia & + & + & + & + & + & + \\
\hline Incoordination & + & + & + & + & + & + \\
\hline (Ilub feet & - & + & - & + & + & + \\
\hline $\begin{array}{l}\text { Abnormal toe implanta } \\
\text { tion }\end{array}$ & - & + & + & + & - & + \\
\hline $\begin{array}{l}\text { Proximally implanted } \\
\text { or short thumb }\end{array}$ & $t$ & + & + & + & + & + \\
\hline $\begin{array}{l}\text { Ocular anomialies (fun } \\
\text { doscopic) }\end{array}$ & + & + & + & - & - & + \\
\hline Genital anomalies & - & + & + & - & - & + \\
\hline Comgenital heart distatse & + & + & + & - & + & - \\
\hline
\end{tabular}

transversality of the palm ridges. The higher the modal type of the $D$ line the greater the thanswersality of the palmar ridges. The main line index was used as another measure of the tratnsiersality of the palman ridges. It incorporates the terminations of both the A and the $\mathrm{D}$ lines. [2. 3]: $(\cdot /)$ presence of patterns in the palmar configurational areas (hypothenar, thenar/I, II, III, and IV); (5) presence of accessory triadii; (6) width of the atd angle; and (7) presence of simian creases. In addition, the general morphology of the palms was scrutinized.

Statistical comparisons were made between the patticnts and their parents and sibs, as well ats between the patients and comol lamilies whenever possible.

\section{Results}

The pertinem dermatloglyphic features of all members of the pat ients' lamilies are shown in Table II. Signiticant diflerences were observed in fingerporint patterns and main line terminations.

\section{Fingerprints}

The pattents have an excess of whorls even when they are compancel with their own siblings and parents. Figure 2 presents the salme ditta in terms of pattem intensity index and shows clearly that with exception of family $I T$ the pattients have the highest inten- sity index within their family groups. The mean pattern intensity indices were: $17.1 \pm 0.61$ for patients, $11.6 \pm 0.36$ for parents, and $10.5 \pm 0.90$ for sibs. The difference between patients and parents or sibs was significant $\left(I^{P}<0.0 \mathrm{I}\right)$ as determined by the $t$ test.

The average pattem intensity index of two parents (the micl-parent value) was calculated for each family in the study. The intensity index of each child was compared with that of the corresponding mid-parent (Fig. 3). If the child's inclex wats higher than that of his mid-parent, he was recorded on the left side of Figure 3 , if lower on the right. The differences between midparent and oflspring were coded for convenience so that 0 signifies a difference of less than $1,1=1$ to 2.9 , $2=3$ to 4.9. and so on. The distributions of the mid-parent 7 s. offspring differences in the patients', siblings, and controls (Fig. 3, $b$ and $r$ ) are very similar to each other and are suggestive of a normal curve. Mll of the patients' indices, however, are clearly higher than those of their mid-parent (Fig. 3a). The similarity of rigures $3 b$ and $3 c$ suggests that the higher pattern intensity score of the patients is due to their inherent differences which are not shared by their nomal sibs.

Total ridge counts of the patticnts and their relatives are shown in Table II. The patients have a signifcantly higher $(P<0.05)$ ridge coum than their par-

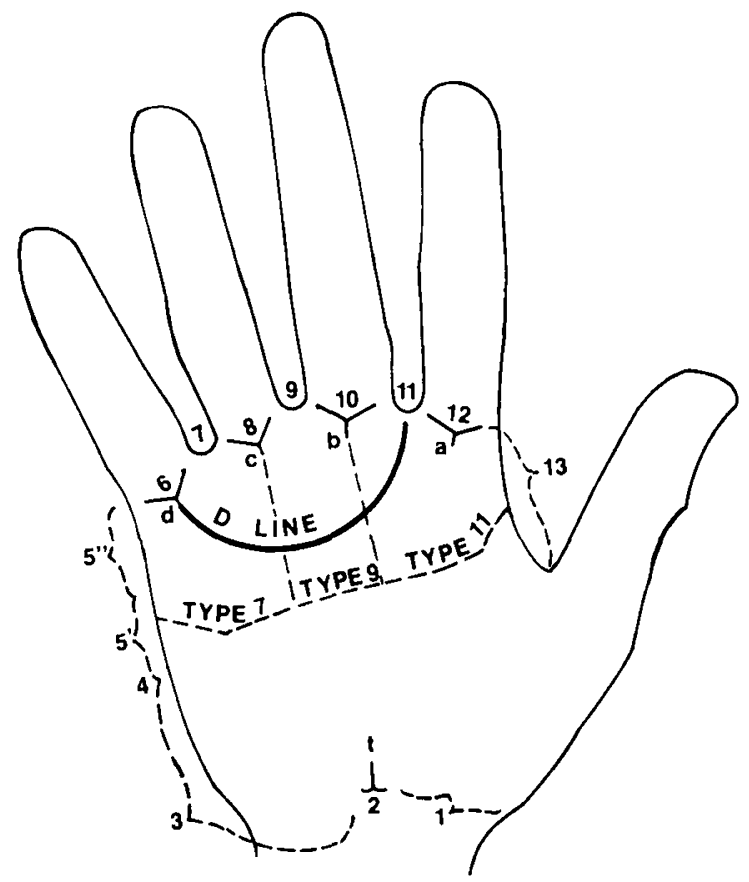

Fir. I. The atreas of the medial types of the 1) line of the pallm.

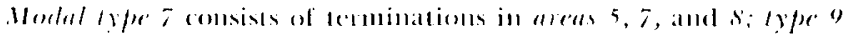
for tomination in " and 10 , and type $1 /$ for teminations in areas 11,12 , and 13 . 


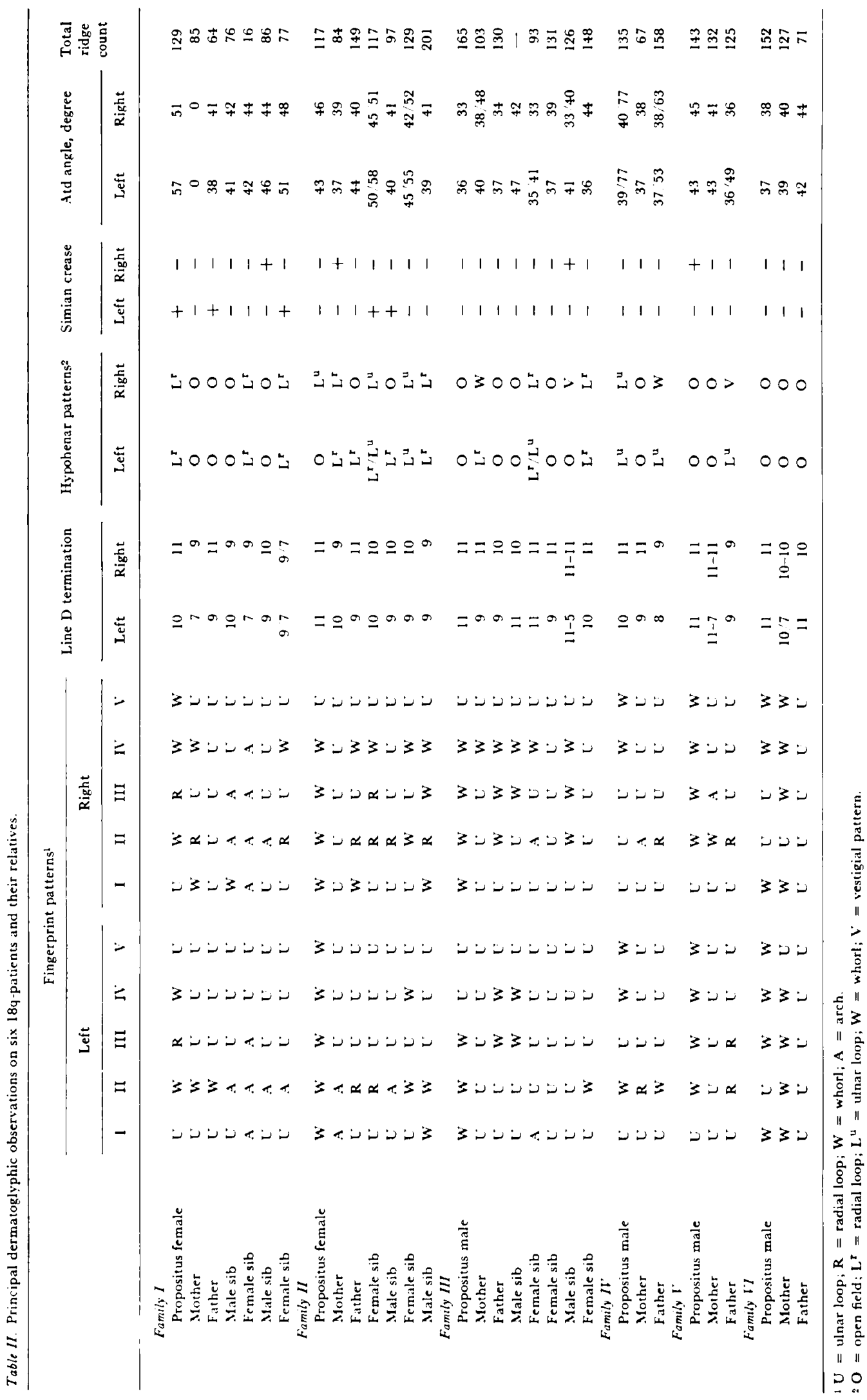




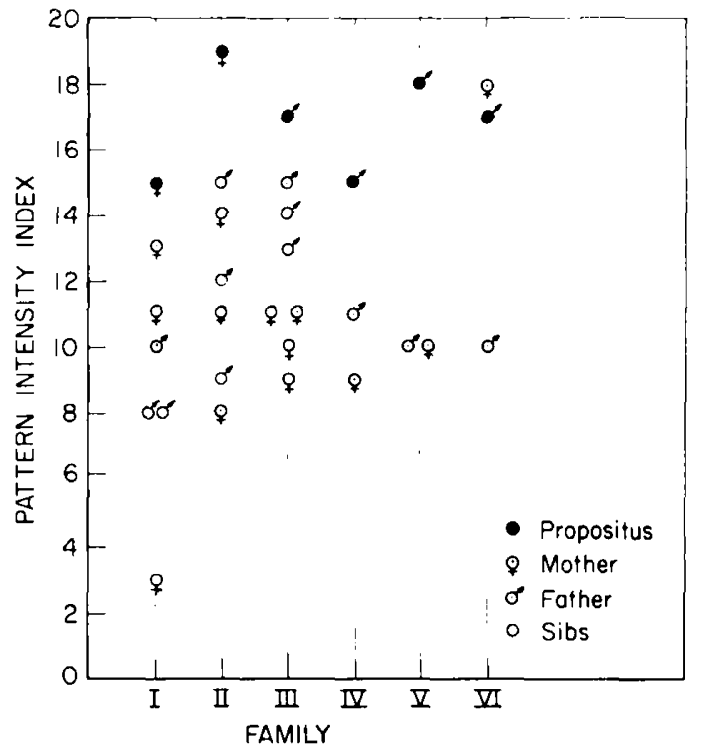

Fig. 2. The pattern intensity indices of patients with the syndrome $18 \mathrm{y}$ - and their first degree relatives.

ents' or mid-parent value. On the average the patients also have a higher ridge count than their sibs; however, this difference is not statistically significant.

\section{Main Line Terminations}

The percentage distribution of the modal types of line D is shown in Figure 4, from which the following conclusions could be drawn: (1) the modal types of the $D$ lines of the patients are much higher than those of their parents (Fig. 4a); (2) the distribution of modal types of the normal sibs of the patients and their parents are similar to each other (Fig. $4 b$ ), and both differ from that of the patients; (3) the modal types of the control parents and their children are also similar to each other (Fig. 4c); and (4) there is striking similarity in the correlation observed for the parents and their normal offspring of both the patient and the control families (Figs. 4, $b$ and $c$ ).

The modal types of the patients, their parents, and their sibs were compared with each other by contingency chi-square tests. Significant differences $(P<$ $0.01)$ were found in comparisons of patients with parents or sibs. Comparisons of parents and normal sibs were not significantly different.

The mean of the main line indices for the patients was $10.33 \pm 0.60$, for the parents, $7.83 \pm 0.66$, and for the patients' sibs, $8.50: \vdash 0.38$. Again, significant differences were found when the patients were compared with their normal sibs $(P<0.05)$ or parents $(P<0.01)$.

There were no significant differences between pa- tients and their parents or sibs in the following comparisons: patterns in the palmar configurational areas, number of accessory interdigital or axial triradii, width of the atd angles, and incidence of simian crease.

At first impression the palms strike the observer ats being unduly long. The thumbs are proximally implanted and frequently appear short. The first metacarpal may also be short. The thumb is often rotated radially along its longitudinal axis, so that when at rest, its palmar surface faces almost the same plane as that of the other fingers. The end of the distal flexion crease frequently tends to point toward the radial palm border or the proximal flexion crease rather than the index area.
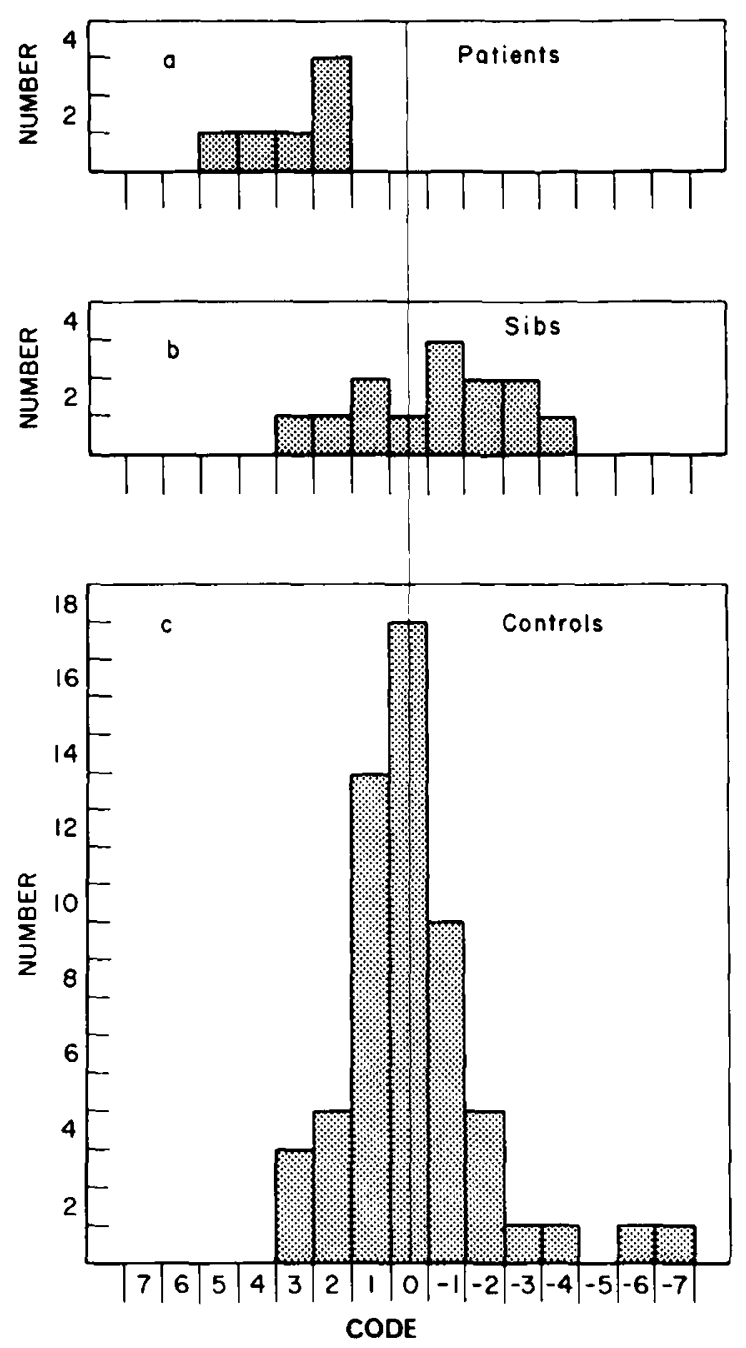

fig. 3. Deviations of the pattern intensity indices of pattients with 1 seg-syndrome, their normal sibs, and notmal controls from that of their respective mid-parent intensity index. (Sce text for code explanation.) 


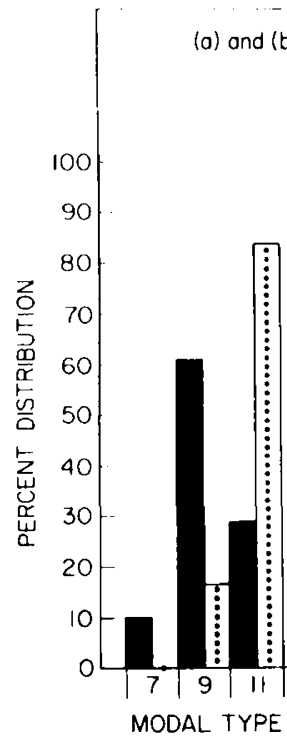

(a)

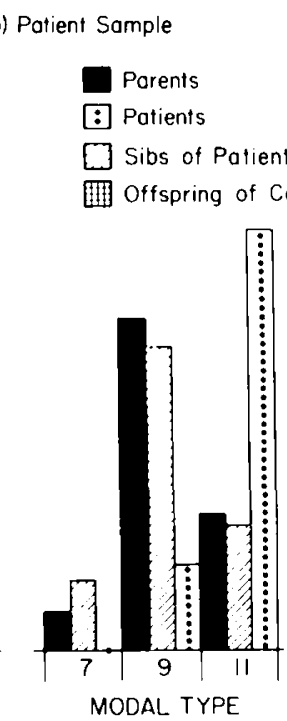

(b) (c) Control Sample

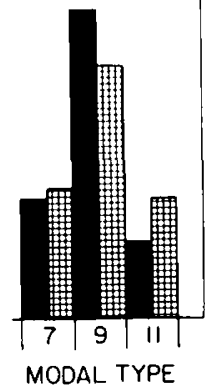

(c)
Fig. 1. The distribution of the modal type of the 1) line of the pattents with loy-syndrome and their parents $(a)$ : the $1 x_{1-1}$, their parents, and their sibs $(b)$; and the control subjects and their partents $(r)$.

\section{Lischssion}

The Isy-syndrome, although more recently identified, could be as firequent as the better known "rri du chat" clisorder (5p-). The typical clinical signs frequently suggest the diagnosis prior to the confirming chromosome analysis. The dermatoglyphic alterations are also part of the overall dysmorphic complex of this syndrome. The present study confirms prior suggestions that the high frequency of whorts may be used as one of the diagnostic signs of this syndrome. The transversality of the D) line may serve as another characteristic of diagnostic value, particularly since it is not a result of, or associated with, higher axial triratii or the presence of hypothenar patterns. This feature has not been stressed before, although it is seen in the palm prints shown in several previous reports $[4,9,10,12$, 1.31.

We noted in published photographs that high pattern intensity index and high modal type (number) of the $\mathrm{D}$ line is also present in patients with ring chromosome $18(18 \mathrm{r})[1,5,6,8]$. This similarity is not surprising in view of the belief that the formation of a ring chromosome involves the loss of chromosomal material from both the long and short arms. For the stated reasons, a search for dermatoglyphic features found in 18y-conlal be applied to the $18 \mathrm{r}$ anomaly.

Most dermatoglyphic chanacteristics are believed to be inherited through polygenic factors. In our study this is supported by the very close similarity between mid-parent values and their normal offspring.

The pattern intensity index and the transversality of palmar riclges of the patients are distinctive not only in terms of absolute values but also in the lack of correlation to the values of the normal family members. Therefore, the use of such dematoglyphic features for diagnostic purposes is enhanced when entire families are studied. Occasionally patients having the I8q-syndrome with low pattern intensity index will be found but still will be distinctive from the remaining family members.

\section{Summary}

Studies of dermatoglyphic patterns were carried out on 6 patients with $18 \mathrm{y}^{-\mathrm{syn}} \mathrm{n}$ (rome, their parents, and normal sibs; 19 normal families were studied as controls.

Significant differences between the patients and normal subjects were observed in: (1) fingerprint pattern intensity index (excess of whorls): and (2) transversality of the palm ridges as shown by the modal type of the D line and the main line index.

No differences were found in the incidence of simian creases, width of the atd angle. number of accessory triardii, and palmatr interdigital patterns.

The comparisons used in this study acquire greater significance when the dermatoglyphic features of the patients are considered not in terms of absolute values, but compared with those of first clegree relatives.

\section{Refermeres and Noles}

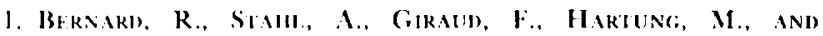
BRtsQut, Y.: Fncéphalopallic ave dysmorphic complexe et chromoseme 17-18 en anneall. Amm. Pediat. 12: 2199 (1966).

2. Commos, H.: Methodology in palmat dermatoglyphics. In: Measures of Men. Midelle American Research Series, p. 23 (Tulane Iniversily, New Orleans, publ. 7, 1936).

3. Cumotos, H., Ano Mumo, C.: Fingerprints, Palms and Soles, p. St (Dover, New York, 1961).

4. me (ikolcens, J.: Chromosome 18: A topologic approach. J. Pediat.. 66: 11.4 (196is).

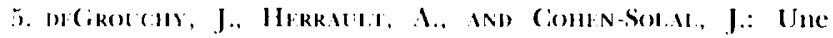
observalion du chomosome is (11 ammean (18r). Ann Genct., 11: $33(1968)$

6. m(ikotchy. J., Romir. P.. Samon, C., and I.amy, M.: Délétion particlle des bras longs du chromosome 18. Pathol. Biol., 12:579(1964).

7. Hort, s.: 'The (ieneties of Dermal Ridges (Thomas, springHe.le., III., I!)(6x).

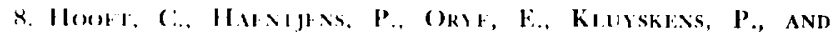

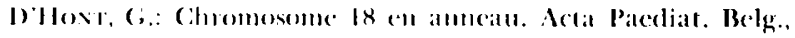
22: 69 (1968). 
9. I.tJ Gne, J., Bragik, R., Lafoukcade, J., and Rethoré, M. O.: Ia dététion partielle du bras long du chromosome 18. Individualisation d'un movel itat morlside. Ant. (ience, 9: 32 (I!)ivi).

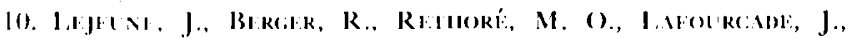

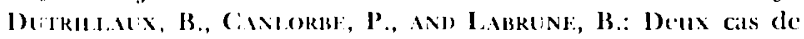
stuchome $18 \mathrm{q}^{-}$en mosaique (46, Xx/46, XX, 18(-). Ann. (ienct., $l 0:$ Is (19967).

11. Niswanink, J. 1), Axb Aosus, M. S.: Major malformations in relatives of oral cleft pattients. Acta Genet., $18: 299$ (1968).

12. Rimwlan, 11., Gorman, L. Z., and Wolf, U.: Defiziemz am langen Arm eines chromosoms. $\mathrm{N}_{1}, 18 \quad(46, \mathrm{XX}, 1 \mathrm{~K}(\mathrm{I}-) . \%$ Kinclerheilk., 101: 152 (1967).

13. Vatmanis, A., Prakson, G., Strgil., A. E., Holksima, R. H., Ax) MaNe, J. D.: A pedigree of $4 / 18$ translocation chromo. somes with type and countertype partial trisomy and partial monosomy for chromosome 18. Amn. Genct., 10: 159 (1967).

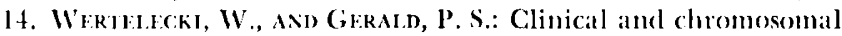
studies of the 18 y- syndrome. J. Pediat. (in press).
15. Wirlitich, W., Schindlek, A. M., and Gerald, P. S.: Partial deletion of chromosome 18. Lancet, $i i: 641$ (19606).

16. Supponted in pall by National Foumdation-Manch of Dimes

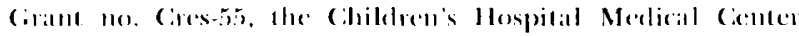
Mental Relardation and Human Development Research Program Giant 110. 111) 03-(0773, and National Institutes of Heallh Research (irame no. H1) 0272.4.

17. Reyuests for reprints should be addressed to: Chris C. Plato, (hildren's Diagnostic and study Branch, National Institute of Child Health and Human Development, National Institules of Health, Bethesda, Mol. 20014 (LSA). The present addeless of 1)r. Wertelecki is the Fpidemiology Branch, Nalional Cancer Institute, National Institutes of Ilealth, Bethesta, Mel. 20014; of Dr. (ierald, Clinical Genetics Division, Boston Chiderens Hospital Medical Center, Boston, Mass.; and of Dr. Niswander, Human Genctics Branch, National Institute of bental Research, National Institutes of Health, Berliesda, Mal. 20014.

18. Accepted for publication April 17, 1970. 